\title{
Information System For Making Vexel Art In Android-Based Photoshop
}

\section{Sistem Informasi Pembuatan Vexel Art Di Photoshop Berbasis Android}

\author{
Silvando Rengga Arnanta ${ }^{1 *}$ \\ \{renggaarnanta@gmail.com\} \\ Universitas Muhammadiyah Sidoarjo
}

\begin{abstract}
The purpose of this research is to make an android-based application that contains ways to make vexel art using Photoshop so that it makes it easier by using a mobile method and there is no need to search first on an internet browser. The method is by observing or observing in the social media group community and the surrounding community who admire or are interested in digital vexel art. The results of this information system run well according to the program and the tutorial is quite detailed and easy to understand. So according to the explanation above this application can provide a good tutorial.
\end{abstract}

Keywords - author guidelines; Jurnal UMSIDA; article template

\begin{abstract}
Abstrak Tujuan dari penelitian ini ialah membuat sebuat aplikasi berbasis android yang berisikan bagaimana caracara membuat vexel art dengan menggunakan photoshop sehingga mempermudah dengan cara mobile dan tidak perlu mencari terlebih dahulu di browser internet. Metode dengan cara observasi atau mengamati di komunitas grub sosial media dan masyarakat sekitar yang mengagumi atau tertarik dengan seni digital vexel art. Hasil dari sistem informasi ini berjalan dengan baik sesuai yang diprogam dan tutorial-nya cukup detail dan mudah dipahami. Jadi menurut penjelasan diatas aplikasi ini dapat memberikan tutorial dengan baik.
\end{abstract}

Kata Kunci - Android; Vexel Art; Photoshop

\section{Pendahuluan}

Dijaman serba teknologi ini akan berdampak pada masyarakat yang akan dituntut menggunakan teknlogi, itu berlaku juga pada seni menggambar yang biasanya menggunakan kanvas, cat, kuas, dan sebagainya berubah menjadi seni digital. Dengan teknologi, seni akan semakin menudahkan bagi masyarkat yang masuk dibidang seni salah satu nya seni rupa.

Photoshop adalah perangkat lunak pengolah gambar dan kata, tetapi photoshop versi baru juga bisa mengelolah video. Perangkat lunak ini sering digunakan untuk mengedit gambar/foto, memanipulasi gambar/foto, menggambar, dan sebagainya.

Vexel art adalah sebuah teknik menggambar (ada yang bilang pengeditan) foto atau gambar melalui perangkat lunak pengolah gambar berbasis bitmap, salah satunya photoshop. Meskipun dibilang menggambar teknik ini bisa menggunakan mouse jadi tidak usah bingung bila tidak mempunyai pentab. Teknik ini sangat ramai digunakan untuk bisnis freelance dikalang para pemuda karena teknik ini fleksibel hasilnya dari kartunisasi, animestyle, minimalis color, line art, dan banyak lagi. Hasil dari vexel art bisa digunakan sebagai hiasan ruangan dengan pigora, foto pernikahan, dijual online dan ada pun yang memesan untuk banner di jalan [2].

Di Indonesia internet sudah semaikin kencang dan berkembang. Internet dapat digunakan untuk belajar yang akan membuat menambahnya kemampuan membaca, berpikir kritis, dan mengintegerasi sumber bacaan yang satu dengan yang lainnya [1].

Di Indonesia masyarakat sudah banyak yang memiliki komputer individu terutama remaja, siswa, dan mahasiswa. Pada tahun 2017 survei dari Kominfo data kepemilikan komputer di Indonesia menunjukkan $7.97 \%$ memiliki komputer, berdasarkan usia 9-19 tahun menunjukkan 7.17\% dan pada usia 10-29 tahun menunjukkan $8.56 \%$. Kepemilikan laptop 21\%, kepemilikan laptop berdasarkan umur 9-19 tahun menunjukkan 15,94\%, umur menunjukkan 20-29 tahun mencapai 27,59\% [3]. Untuk meningkatkan produktifitas butuh pengetahuan dan tutorial. Jadi dibutuhkan platform yang mudah dijangkau untuk semua orang yaitu android. Di indonesia android sudah terjual hampir diseluruh Indonesia, berbagai merk dan harga pun ada. Tingkatan kepemilikan smartphone individu di Indonesia menunjukkan $66,31 \%$. Untuk internet, penggunaan individu di Indonesia pada umur 9-19 tahun mencapai 43,90\% untuk umur 2029 tahun mencapai $60,15 \%[4]$.

Disisi lain tidak semua para remaja, siswa atau siapapun itu kurang memiliki produktifitas dirumah (dipembahasan ini dikhusukan bagi yang memepunyai komputer atau laptop). Mereka mempunyai komputer atau laptop biasanya hanya digunakan untuk game, menonton film, tugas sekolah dan ada juga yang disimpan saja jarang dipakai.

Dengan memanfaatkan teknologi, pengatahuan dan keahlian sehingga meningkatkan produktifitas dan bisa juga dibuat untuk pekerjaan freelance dalam pembuatan vexel art[5]. 


\section{METODE}

\section{A. Sistem informasi}

Sistem informasi merupakan sistem yang menyediakan informasi sedemikian rupa yang bermanfaat bagi penerima(Nurlalela,2013). Sistem informasi gabungan kerja sama dari hardware, software, dan brainware untuk mengolah data yang nantinya dapat bermanfaat bagi penerima.

\section{B. Aplikasi}

Aplikasi merupakan suatu program yang digunakan untuk menjalankan suatu tugas atau fungsi sesuai dengan sistem pemrograman yang di jalankan. Aplikasi dapat memecahkan masalah menggunakan teknik pemrosesan data aplikasi cenderung pada komputasi yang diinginkan.

\section{Android studio}

Android Studio merupakan IDE (Integrated development Enviroment) software yang dikembangkan langsung oleh pihak android atau Google yang bersifat open source dan gratis yang digunakan untuk mengembangkan aplikasi berbasis android.

\section{Adobe photoshop}

Adobe Photoshop adalah perangkat lunak pengolah gambar dan kata, tetapi photoshop versi baru juga bisa mengelolah video. Perangkat lunak ini sering digunakan untuk mengedit gambar/foto, memanipulasi gambar/foto, menggambar, dan sebagainya. Ada banyak sekali fitur dan tool yang ada diphotoshop seperti lasso tool, filter, layer, dan sebagainya yang memiliki fungsi tesendiri.

\section{E. Flowchart}

Algroitma yang direprentasikan secara simbolik untuk menyelesaikan suatu masalah. Flowchart sangat berguna salah satunya bagi pengembang software dan diagram alir penelitian untuk menganalisis jalannya program yang akan dibuat.

Tabel 1. Flowchart

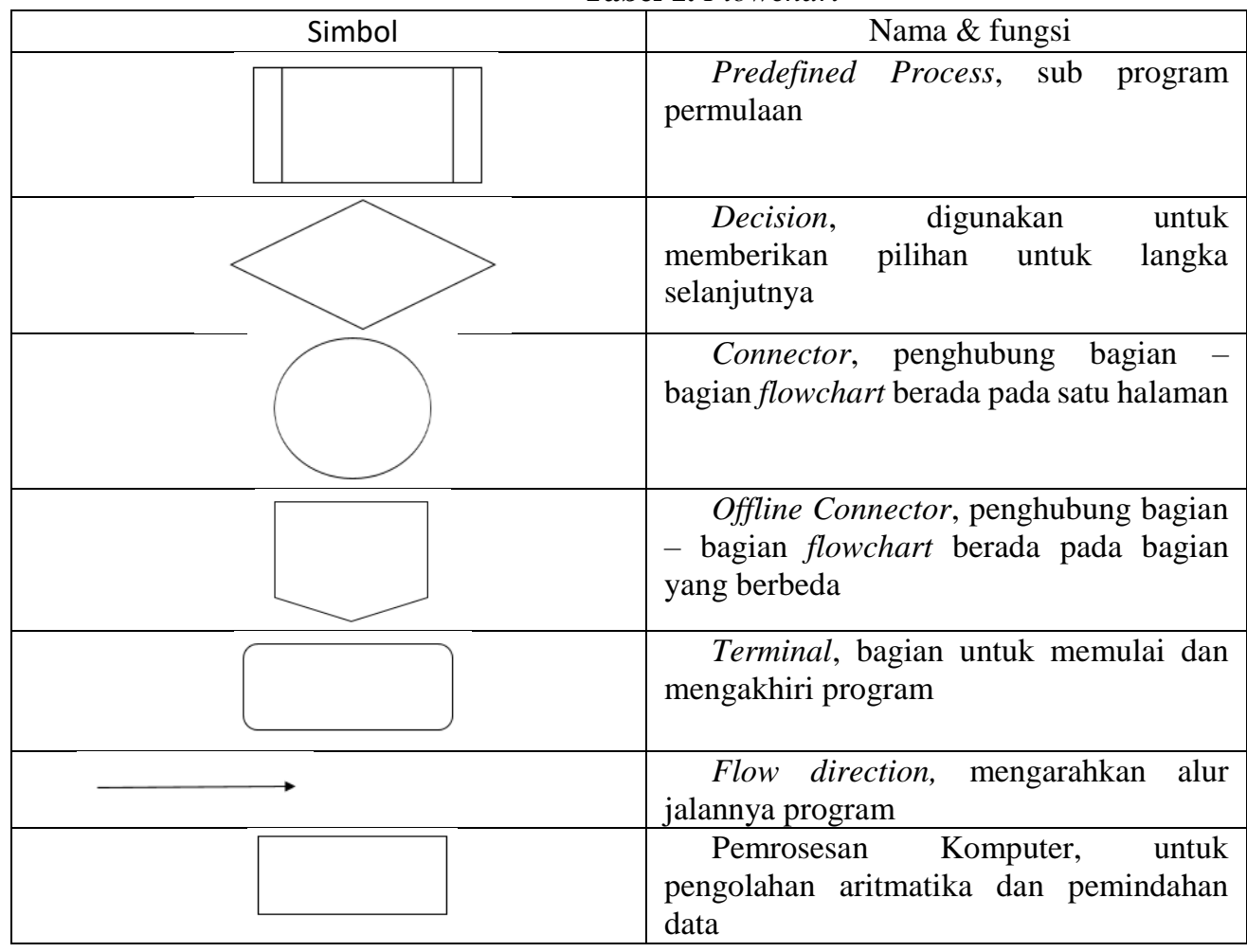




\section{F. Data flow diagram (dfd)}

Data Flow Diagram merupakan diagram yang digunakan untuk menggambarkan suatu entitas ke sistem atau sebaliknya. DFD sangat berguna untuk melihat input output masuknya data.

Tabel 2. Data Flow Diagram

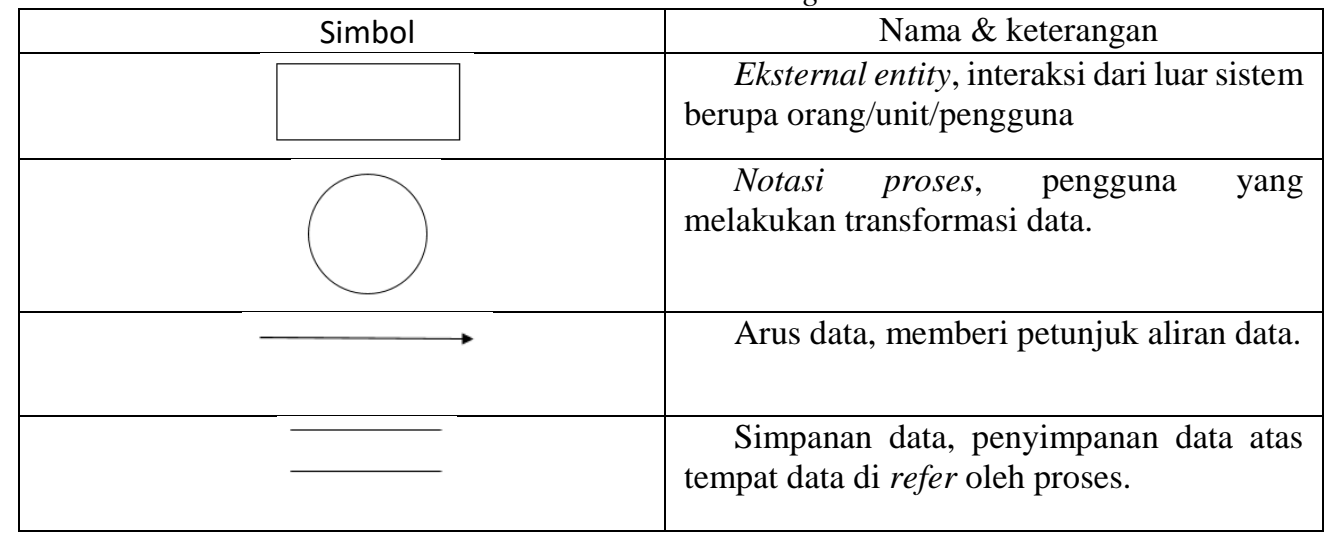

\section{HASIL DAN PEMBAHASAN}

\section{A. Diagram alir penelitian dengan simbol flowchart}

Terdapat tahapan - tahapan yang akan dilakukan untuk melanjutkan penelitian ini dengan menyusun alir penelitian agar dapat berjalan secara teratur. Berikut gambar alir penelitian :

Penjelasan :

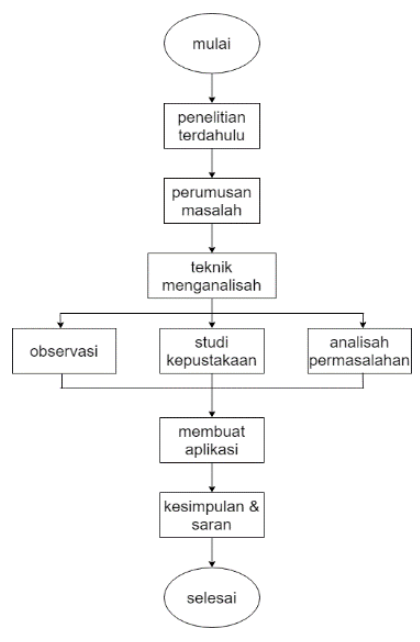

Gambar 1. Alir penelitian

1. Pertama mencari penelitian terdahulu agar mengerti permasalahan yang akan diteliti.

2. Lalu memikirkan rumusan masalah yang dibuat untuk memfokuskan penelitian.

3. Kemudian melakukan teknik menganailisah agar hasil penelitian mendapatkan hasil yang maksimal. Teknik menganalisah yang digunakan ada 3 yaitu observasi (di penelitian ini menggunakan metode pengamatan), Studi kepustakaan dengan mencari referensi-referensi yang sudah ada sebelumnya, dan Analisah permasalahan untuk menentukan batasan masalah.

4. Jika sudah mendapatkan data-datanya langsung membuat aplikasi penelitian. Bila sudah selesai buat kesimpulan dan saran untuk aplikasi yang dibuat tadi tentang kelebihan dan kekurangannya. 


\section{B. Flowchart}

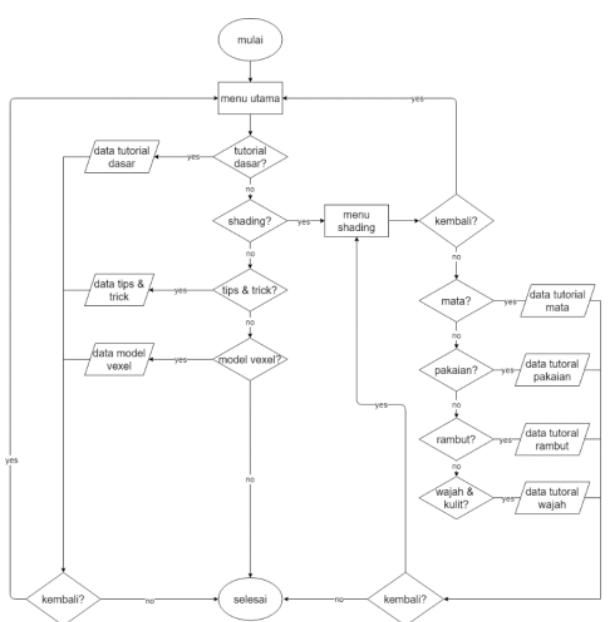

Gambar 2. Flowchart

Penjelasannya :

1. Pertama pengguna ketika membuka aplikasi yang langsung menuju halaman utama aplikasi.

2. Di halaman utama ada 4 tombol yaitu tutorial dasar, shading, tips \& trick, dan model vexel.

3. Ketika salah satu tombol di tekan atau di sentuh akan langsung menampilakkan isi dari tombol yang ditekan tadi. Kecuali untuk tombol shading karena nanti ada tombol pilihan lagi yang menampilkan beberapa tutorial mata wajah, pakaian, rambut, dan wajah \& kulit.

4. Pengguna juka bisa kembali ke menu berikutnya dan memilih tombol lainnya.

\section{Dfd level 1}

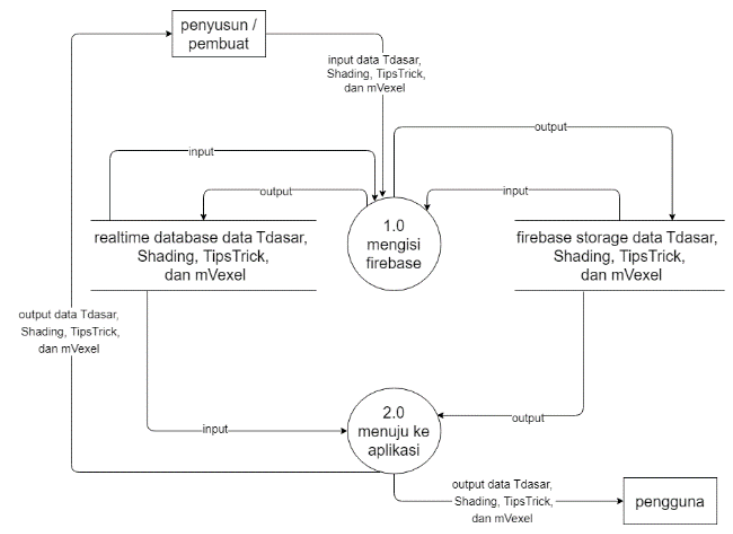

Penjelasan :

Gambar 3. DFD level 1

1. Penyusun menginputkan data Tdasar, Shading, TipsTrick, dan mVexel ke firebase.

2. Dan input dan outputnya terpecah menjadi 2 database realtime untuk bagian dalam bentuk data teks dan firebase storage untuk bagian dalam bentuk gambar.

3. Output dari 2 pecahan tadi masuk ke firebase dan aplikasi.

4. Data yang masuk ke aplikasi tadi bisa dilihat oleh pengguna dan penyusun/pembuat. 
Procedia of Engineering and Life Science Vol. 1. No. 1 March 2021

Seminar Nasional \& Call Paper Fakultas Sains dan Teknologi (SENASAINS 1st)

Universitas Muhammadiyah Sidoarjo

\section{Struktur firebase storage dan realtime database}

Tabel 3. Struktur realtime database

\begin{tabular}{|l|l|}
\hline \multicolumn{1}{|c|}{ Nama field } & type \\
\hline Name & Text \\
\hline Value & Text \\
\hline
\end{tabular}

Tabel 4. Struktur firebase storage

\begin{tabular}{|l|l|}
\hline Nama field & Type \\
\hline file & JPEG, PNG, GIF, dan lain-lain \\
\hline
\end{tabular}

Realtime Database tidak seperti database pada umumnya. Realtime database disini untuk menyimpan data text. menggunakan Name untuk menamai datanya dan Value untuk isi datanya. Value yang sudah terisi nanti langsung tersingkiron kan aplikasi yang dibuat secara realtime. Berikut gambar visualisasinya :
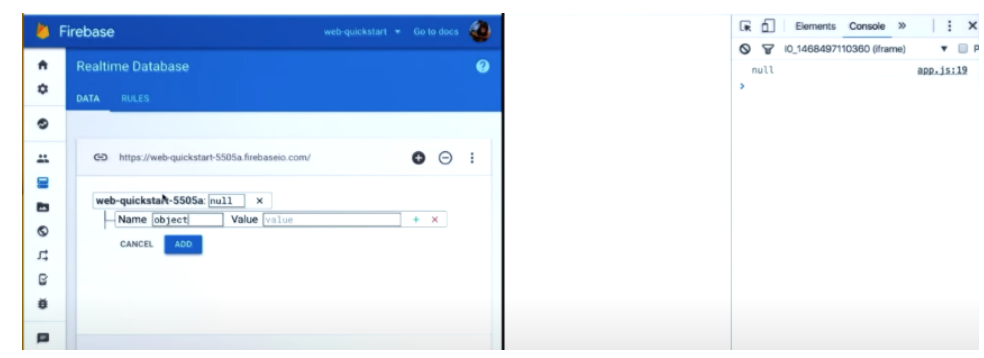

Gambar 4. Visualisasi realtime database 1
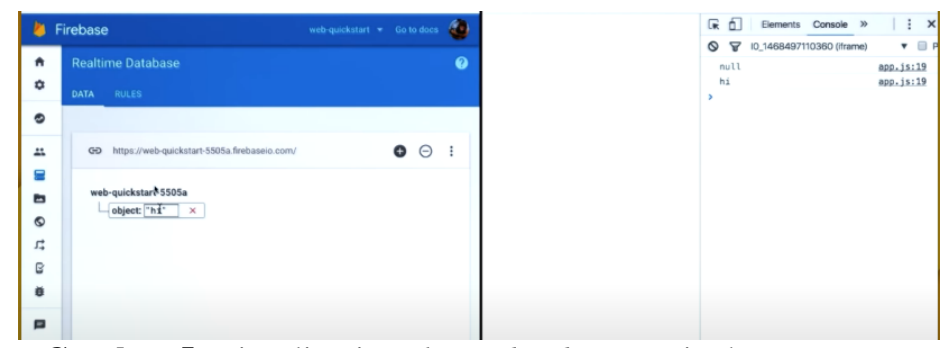

Gambar 5. Visualisasi realtime database tersingkron

Firebase storage di penelitian ini digunakan untuk menyimpan data gambar. Cara kerja sederhananya firebase storage ialah upload \& download. Gambar yang telah diupload di firebase storage akan tersingkronkan ke aplikasi yang dibuat. Berikut visualisasi firebase storage :

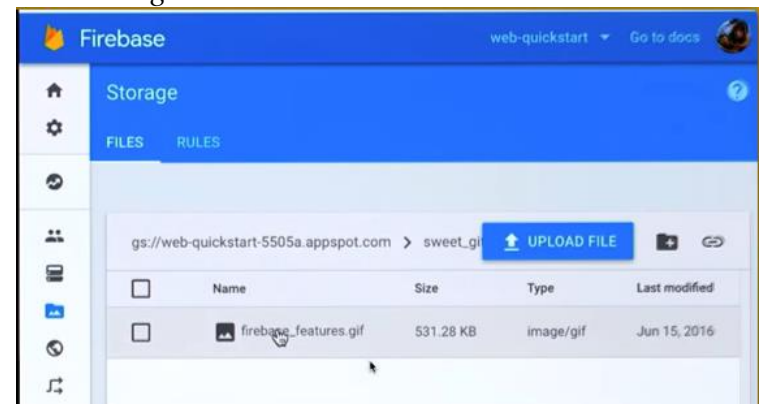

Gambar 6. Visualisasi Firebase Storage

\section{E. Pengujian alpha}

Aplikasi vexel diberikan kepada orang-orang yang ingin mencoba/membuat/belajar vexel art, maka aplikasi harus di uji coba terlebih dahulu agar menemukan kesalahan atau ada yang eror yang terjadi ketika aplikasi berjalan. Pengujian ini menggunakan metode black box:

Pengujian Black box ini mengamati bagian fungsional aplikasi. Jadi aplikasi ini berusaha menemukan eror atau kesalahan antara lain: 
Procedia of Engineering and Life Science Vol. 1. No. 1 March 2021

Seminar Nasional \& Call Paper Fakultas Sains dan Teknologi (SENASAINS $1^{\text {st) }}$

Universitas Muhammadiyah Sidoarjo

1. User interface tidak semestinya.

2. Kesalahan kinerja.

3. Bagian-bagian gambar atau teks yang tidak muncul.

4. Kesalahan penempatan data.

\section{F. Metode pengujian}

Rencana pengujian aplikasi vexel ditabel berikut:

Tabel 5. Rencana pengujian

\begin{tabular}{|c|c|c|}
\hline Item Uji & Detail Pengujian & Jenis Uji \\
\hline Teks sapaan awal & Tampil & Black box \\
\hline \multirow[t]{3}{*}{ UI menu } & UI stabil & Black box \\
\hline & Menampilkan teks & Black box \\
\hline & Menampilkan gambar & Black box \\
\hline \multirow[t]{3}{*}{ UI tutorial dasar } & UI stabil & Black box \\
\hline & Menampilkan teks & Black box \\
\hline & Menampilkan gambar & Black box \\
\hline \multirow[t]{2}{*}{ UI Shading } & UI stabil & Black box \\
\hline & Menampilkan icon & Black box \\
\hline \multirow[t]{3}{*}{ UI Mata } & UI stabil & Black box \\
\hline & Menampilkan teks & Black box \\
\hline & Menampilkan gambar & Black box \\
\hline \multirow[t]{3}{*}{ UI pakaian } & UI stabil & Black box \\
\hline & Menampilkan teks & Black box \\
\hline & Menampilkan gambar & Black box \\
\hline \multirow[t]{3}{*}{ UI rambut } & UI stabil & Black box \\
\hline & Menampilkan teks & Black box \\
\hline & Menampilkan gambar & Black box \\
\hline \multirow[t]{3}{*}{ UI wajah dan kulit } & UI stabil & Black box \\
\hline & Menampilkan teks & Black box \\
\hline & Menampilkan gambar & Black box \\
\hline \multirow[t]{3}{*}{ UI tips \& trik } & UI stabil & Black box \\
\hline & Menampilkan teks & Black box \\
\hline & Menampilkan gambar & Black box \\
\hline \multirow[t]{3}{*}{ UI model vexel } & UI stabil & Black box \\
\hline & Menampilkan teks & Black box \\
\hline & Menampilkan gambar & Black box \\
\hline \multirow[t]{2}{*}{ Burger button } & UI stabil & Black box \\
\hline & Menampilkan teks & Black box \\
\hline \multirow{3}{*}{$\begin{array}{l}\text { Mengolah data } \\
\text { (admin) }\end{array}$} & Edit data & Black box \\
\hline & Menghapus data & Black box \\
\hline & Simpan data & Black box \\
\hline Tombol back/kembali & Berfungsi/tidak & Black box \\
\hline \multirow[t]{2}{*}{ Video } & Stream video & Black Box \\
\hline & Fullscreen & Black Box \\
\hline
\end{tabular}

\section{G. Implementasi sistem}

Ada pula implementasi sistem, implementasinya tentang bagaimana urutan-urutan menggunakan aplikasi vexel bagi pengguna pemula photoshop dan pengguna yang sudah pernah menggunakan photoshop. Berikut penjelasannya :

Awal Dalam Menggunakan Aplikasi

Pada awal membuka aplikasi akan dihadapkan oleh 4+1 tombol yaitu tutorial dasar, shading, tips \& trick, model vexel + burger button. 


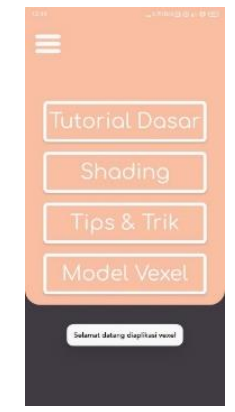

Gambar 7. Awal Dalam Menggunakan aplikasi

Ada 2 menu tujuan yang paling utama disini yaitu tutorial dasar dan shading. Untuk pengguna pemula atau awam tentang photoshop sebaiknya melihat tutorial dasar terlebih dahulu karena disana terdapat dasar-dasar menggunakan fitur dan tool yang ada di photoshop.

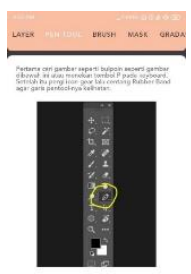

Gambar 8. Awal Dalam Menggunakan aplikasi, pentool

Ketika sudah memahaminya bisa langsung menuju ke menu shading. Untuk pengguna yang sudah paham dengan photoshop maka bisa melewati tutorial dasar langsung saja ke menu shading.

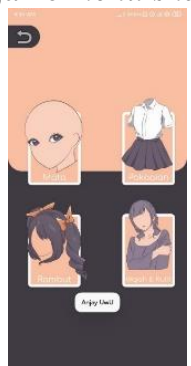

Gambar 9. Awal Dalam Menggunakan aplikasi, shading

Tahap ke menu shading

Dimenu shading terdapat 4 tombol tutorial, pengguna tidak harus melihat secara urut jadi terserah pengguna ingin melihat tutorial yang mana. Setiap tutorial berisi cara shading dan beberapa teknik dalam pembuatan vexel art sesuai bagiannya. 


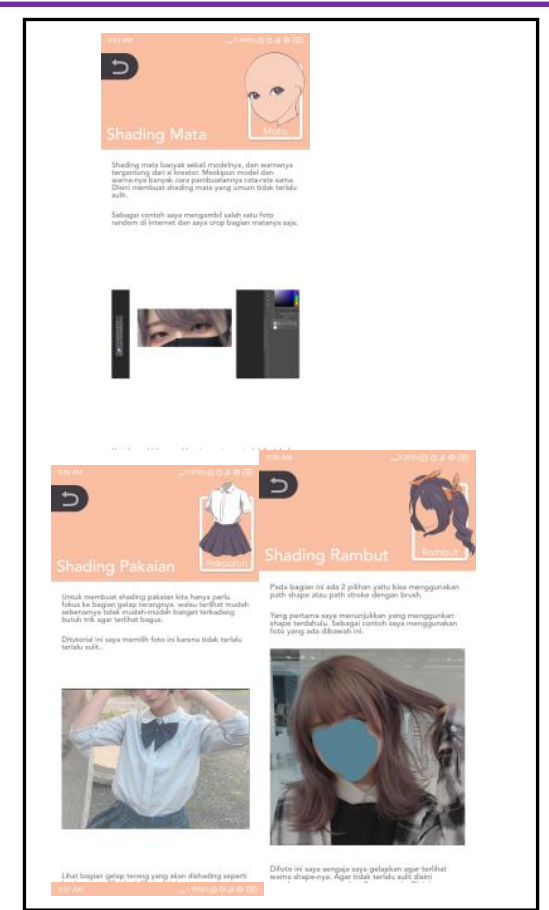

Gambar 10. Tahap ke Menu Shading

\section{Ke menu tips \& trik}

Bagi pengguna terutama pemula memakai photoshop sebelum memulai membuat vexel, sebaiknya meilhat menu ini terlebih dahulu agar dalam pembuatan vexel nantinya tidak terlalu susah dan lebih cepat.

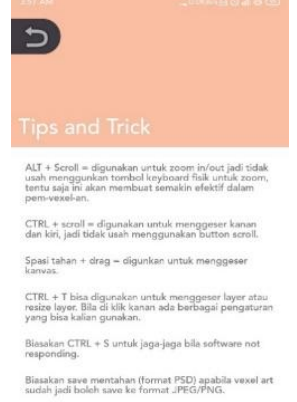

Gambar 11. Ke menu Tips \& Trik

Menemukan inspirasi dengan menu model vexel

Jika sudah belajar membuat vexel atau sudah menyelesaikan cara-cara yang sudah diberikan diaplikasi ini. Bisa mengambil beberapa contoh style yang ada di menu medel vexel ini. Dengan begini pengguna bisa menemukan/belajar membuat style sendiri nantinya dengan mencoba beberapa style yang nantinya bisa dimodifikasi sendiri oleh pengguna. 


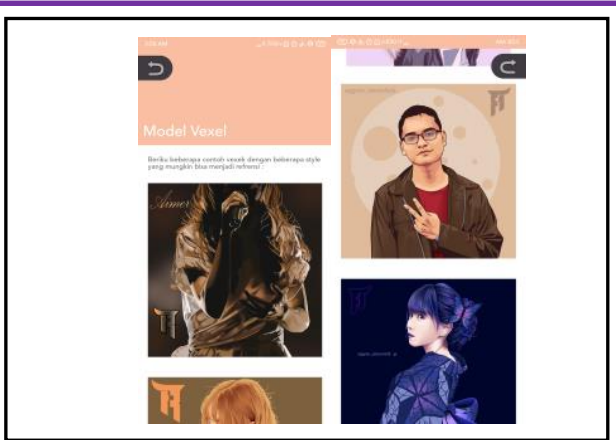

Gambar 12. Menemukan Inspirasi Dengan Menu Model Vexel

\section{KESIMPULAN}

Seperti yang sudah ada di pembahasan, analisis sistem, perancangan dan implementasi Sistem Informasi Pembuatan Vexel Art Di Photoshop Berbasis Android bisa dismpulkan sebagai berikut: Memiliki UI simpel, warna yang digunakan warna pastel dan tidak saling bertabrakan, aplikasinya ringan jadi tidak membutuhkan spesifikasi device yang mahal/tinggi, ukuran aplikasi yang kecil, sehingga tidak memakan ruang storage yang banyak, tutorial lumayan lengkap dan detail.

\section{REFERENSI}

[1] The official training workbook from Adobe Systems. 2012. Adobe Photoshop CS6 classroom in a book. the United States of America: Peachpit.

[2] Fathurrahman Kurniawan Ikhsan, Fatimah Fahurian, Aliy Hafiz. 2019. RANCANG BANGUN APLIKASI CLOUD STO

[3] RAGE DENGAN ANGGULAR DAN FIREBASE BERBASIS ANDROID. Jurnal Management Sistem Informasi dan Teknologi. Vol 9, No 2.

[4] Khairil, Indra Kanedi, Harry Aspriyono.2012.PERMAINAN DALAM PERHITUNGAN PERKALIAN BERBASIS ONLINE MENGGUNAKAN FLASH. Jurnal Media Infotama, Vol.8 No.2, 18 - 36.

[5] Lulu Riskiah Harahap, Agus Priyatno, Osberth Sinaga, dan Onggal Sihite.2020. ANALISIS KARAKTERISTIK VECTOR ART PADA VECTORINA MEDAN COMMUNITY TAHUN 2019 DITINJAU DARI ELEMEN VISUAL. Jurnal Seni Rupa. Volume 09 Nomor 01, 153 - 157. 